amino acids), which was processed to a $99 \mathrm{~K}$ intermediate and cleaved into the $68 \mathrm{~K}$ and $40 \mathrm{~K}$ polypeptides (Fig. $3 b$, lanes 13-18). As would have been expected for proteins lacking signal peptides, no LAV envelope-related polypeptide was detected in the infected cell medium (Fig. $3 c$, lane 4 ) and no $N$-linked glycosylation with ${ }^{3} \mathrm{H}$-glucosamine was observed (Fig. $3 a$, lane 8).

We examined the immunogenicity of proteins expressed by recombinant vaccinia viruses v-env5 and v-env2. Male mice (strain C57BL/6J) were inoculated by tail scarification with $2 \times 10^{7}$ plaque-forming units (PFU) of each of the recombinant viruses. Serum samples were collected at 2 -week intervals for 8 weeks post-inoculation and were analysed by Western blotting for reactivity with LAV virion proteins. By 8 weeks post-inoculation, all animals immunized with the recombinant viruses produced antibodies that reacted with LAV envelope glycoprotein gp41 (Fig. 4). Serum from some of the animals immunized with v-env5 (Fig. $4 a$ and our unpublished results) also recognized gp150 and gp110, indicating the ability of this recombinant virus to elicit an immune response to all major glycoproteins of LAV. Using enzyme-linked immunosorbent assay (ELISA) and Western blot analyses, we found that the LAV-specific antibody titres elicited by both recombinants continued to rise throughout the experiment, and that recombinant v-env5 was also able to elicit LAV-specific responses in an out-bred strain of mouse (ICR) following several routes of immunization (data not shown).

The description of neutralizing antibodies to LAV/HTLVIII $^{13}$ raises the possibility that neutralizing epitopes can be identified and a vaccine formulated for the prevention of AIDS. One promising approach for vaccine development is the use of vaccinia virus as an expression vector ${ }^{14,15}$. A vast database has been established detailing the safety and efficacy of vaccinia virus as a successful smallpox vaccine, and there is an increasing body of knowledge concerning the use of recombinant vaccinia viruses to stimulate humoral ${ }^{16-19}$ and cell-mediated ${ }^{20}$ immunity against various pathogens. The vaccinia-LAV recombinants that we have described here could prove to be useful tools for the study of the antigenic properties of LAV envelope proteins and eventually for the design of an effective vaccine against AIDS.

We thank the staff at Genetic Systems Corporation for assistance, in particular Bruce Travis for providing plasmid pRS-3, Jan McClure for LAV virion proteins and human serum samples, and Elaine Thomas for helpful discussions. The genomic clone of LAV $(\lambda \mathrm{J} 19)^{8}$ was provided by Luc Montagnier. We also thank Tony Purchio for encouragement; Peter Linsley, Jeff Ledbetter and Paul Beaumier for technical advice; and Bonnie Kirk and Anne Little for preparation of the manuscript.

Note added in proof: The immunogenicity of v-env5 has been examined in one species of sub-human primate (Macaca fascicularis). Seven out of 8 vaccinated animals developed specific antibodies to the envelope glycoprotein of LAV.

Received 2 January; accepted 11 February 1986.

1. Gottlieb, M. et al. New Engl. J. Med. 305, 1426-1431 (1981).

Masur, H. et al. New Engl. J. Med. 305, 1431-1438 (1981).

Barré-Sinoussi, F. et al. Science 220, 868-870 (1983).

4. Gallo, R. C. et al. Science 224, 500-502 (1984)

Popovic, M., Sarngadharan, M. G., Read, E. \& Gallo, R. C. Science 224, 497-499 (1984) Levy, J. A. et al. Science 225, 840 (1984).

Curran, J. W. et al. Science 229, 1352-1357 (1985).

Alizon, M. et al. Nature 312, 757-760 (1985)

Wain-Hobson, S., Sonigo, P., Danos, O., Cole, S. \& Alizon, M. Cell 40, 9-17 (1985)

Mackett, M., Smith, G. L. \& Moss, B. J. Virol. 49, 857 864 (1984),

t. Montagnier, L. et al. Virology 144, 283-289 (1985).

2. Robey, W. G. et al. Science 228, 593-595 (1985).

3. Robert-Guroff, M., Brown, M. \& Gailo, R. C. Nature 316, 72-74 (1985).

4. Panicali, D. \& Paoletti, E. Proc. natn. Acad. Sci. U.S.A. 79, 4927-4931 (1982)

15. Mackett, M., Smith, G. \& Moss, B. Proc. natn. Acad. Sci. U.S.A. 79, 7415-7419 (1982).

16. Smith, G. L., Mackett, M. \& Moss, B. Nature 302, 490-495 (1983).

17. Panicali, D., Davis, S. W., Weinberg, R. L. \& Paoletti, E. Proc. natn. Acad. Sci. U.S.A. 80, 5364-5368 (1983).

18. Smith, G. L., Murphy, B. R. \& Moss, B. Proc. natn. Acad. Sci. U.S.A. 80, 7155-7159 (1983).

19. Paoletti, E. et al. Proc. natn. Acad. Sci. U.S.A. 81, 193-197 (1984).

20. Bennick, J. R. et al. Nature 311, 578-579 (1984)

21. Maniatis, T., Fritsch, E. F. \& Sambrook, J. (eds) Molecular Cloning: A Laboratory Manual (Cold Spring Harbor Laboratory, New York, 1982)

\section{Requirement for c-ras proteins during viral oncogene transformation}

\author{
Mark R. Smith*, Steven J. DeGudicibus* \\ \& Dennis W. Stacey
}

Roche Institute of Molecular Biology, Roche Research Center, Nutley, New Jersey 07110, USA

* Present addresses: National Cancer Institute, National Institutes of Health, Frederick, Maryland 20205, USA (M.R.S.); Institute for Therapeutic Research, Merck Sharp \& Dohme, Rahway, New Jersey 07065, USA (S.J.DeG.).

Many retroviral oncogenes have been classified into one of several categories based on structure, enzymology and cellular localization ${ }^{1}$. These genes originated from host cells and are probably derived from genes normally involved in the control of cell proliferation ${ }^{2}$. The cellular counterparts of three oncogenes have been identified as a growth factor or growth factor receptor ${ }^{3-6}$; related oncogenes include receptor-like membrane proteins which often express tyrosine kinase activity. These growth factor-related oncogenes are structurally and biochemically distinct from the membrane-associated ras gene family, which bind and hydrolyse GTP $^{7-9}$. Oncogenes localized primarily in the cytoplasm which probably have serine kinase activity, have also been identified ${ }^{10-12}$. Although the structure and biochemistry of many oncogenes have been extensively studied, relatively little is known about the functional relationships of oncogene proteins within the cell. An opportunity to study such interaction is provided by the identification of a monoclonal antibody that neutralizes cellular ras proteins when microinjected into cells ${ }^{13}$. It has been shown previously that the injected antibody inhibits the initiation of S-phase in NIH 3T3 cells ${ }^{14}$. In the present study we injected this monoclonal antibody into NIH 3T3 cells transformed by a variety of oncogenes. The results show that transformation by three growth factor receptorlike oncogenes depends on c-ras proteins, while transformation by two cytoplasmic oncogenes appears to be independent of c-ras protein.

Anti-ras monoclonal antibodies originally prepared by Furth et $a l^{15}$ have been analysed extensively. Monoclonal antibody Y13-259 (which binds the c-ras proteins of a variety of species ${ }^{15}$ ) neutralized the activity of co-injected, purified ras protein, and

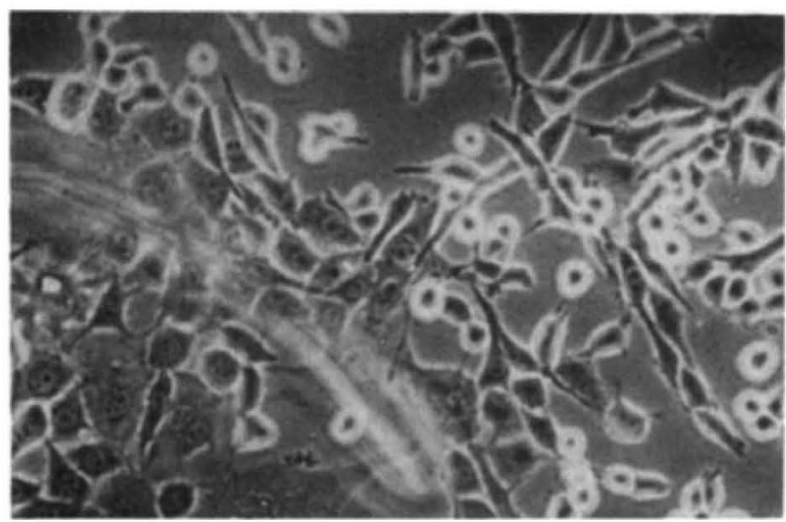

Fig. 1 Morphological reversion of src-transformed cells following injection of anti-ras antibody. These NIH 3T3 cells were transformed by the Rous sarcoma viral genome (see Table 1). Neutralizing anti-ras antibody 259 was injected into the cells adjacent to or within a circular mark on the underside of the coverslip to which the cells were attached. A small section of this circular mark is visible, allowing identification of the injected area in the lower left half of this phase-contrast photomicrograph $(\times 82)$. After $16 \mathrm{~h}$, cells in the injected area had reverted to the flattened, non-refractile apperance of untransformed cells. The nuclei of most injected cells, for example, are clearly visible. Uninjected cells (or cells injected with control antibody 238; data not shown) remained refractile, with the spherical or spindle shape of transformed cells. 
Fig. $2{ }^{3} \mathrm{H}$-thymidine incorporation into $\mathrm{NIH}$ 3T3-transformed cells after antibody injection. NIH 3T3 cells transformed by the fes $(a, b)$ or fms $(c, d)$ oncogenes (see Fig. 1), the bovine papillomavirus $\left(e, f\right.$; from D. R. Lowy $\left.{ }^{25}\right)$, or the mos oncogene $(g, h)$ were grown as a uniform monolayer. Cells within a small circle marked on the back of the coverslips were injected with antibody 259 . After $18 \mathrm{~h}$ the cells were pulsed with ${ }^{3} \mathrm{H}$-thymidine and stained with a fluorescent antibody that recognizes injected antibody within the cells ${ }^{16}$. Fluorescence photomicrographs (left) indicate that almost all the cells in the centre of the photographs were successfully injected. Few fms or fes-transformed cells incorporated thymidine after injection, while a definite reduction with BPV-transformed cells was observed. No reduction in thymidine incorporation was observed in mostransformed cells.
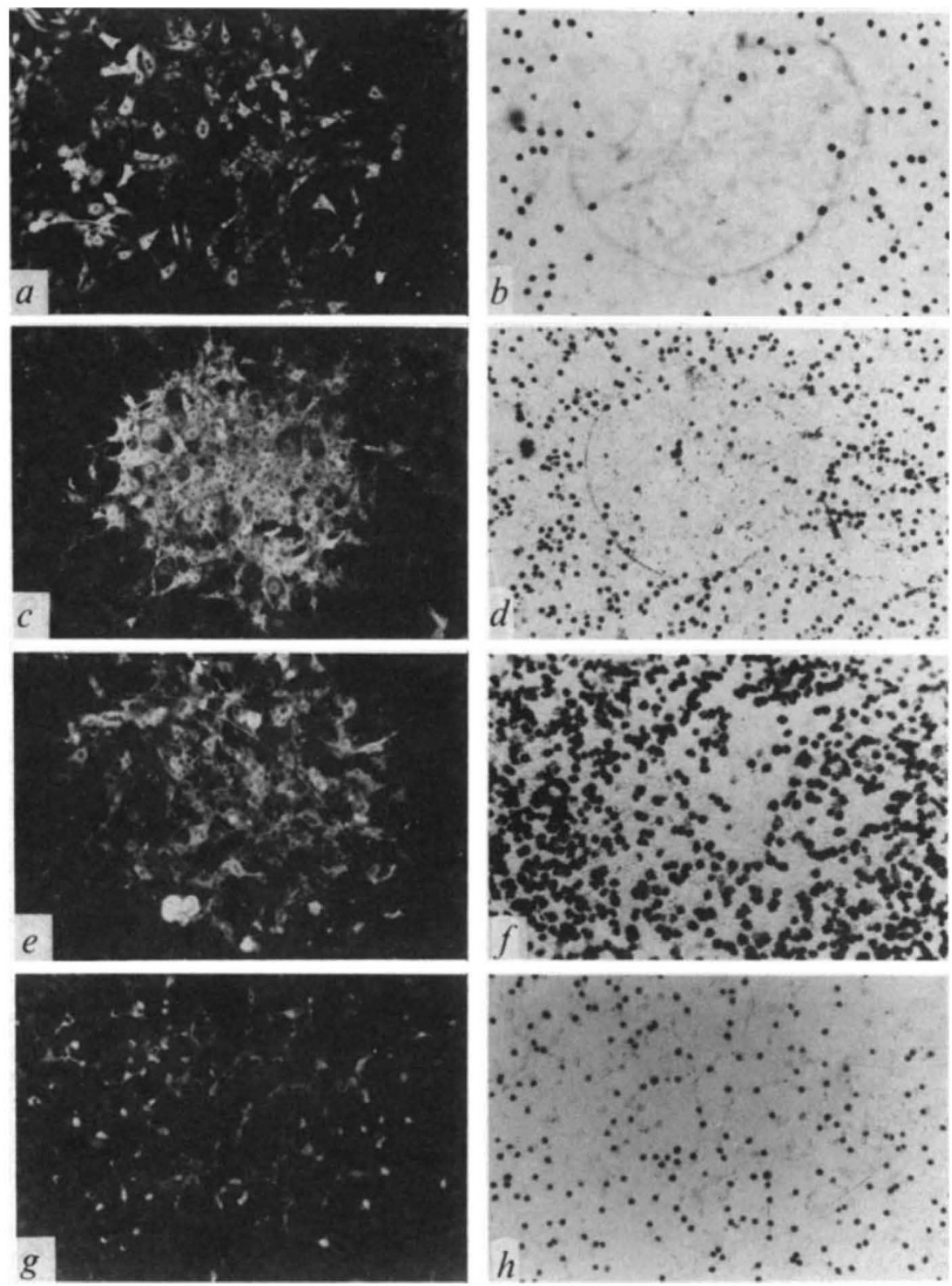

induced a morphological reversion to the normal phenotype in ras-transformed NIH 3T3 cells. Antibody Y13-238 neither neutralized co-injected protein nor affected ras-transformed cells ${ }^{13}$ and was used as a negative control. When neutralizing antibody 259 was microinjected into untransformed NIH 3T3 cells, their rate of proliferation was decreased by approximately $90 \%$ compared with either uninjected cells or cells injected with control antibody 238 . The antibody inhibited only the initiation of a new round of DNA synthesis. Inhibition was observed until just before the initiation of S-phase but did not affect a cycle of DNA synthesis once it had begun ${ }^{14}$. Cell lines tested in this study were therefore pulsed for $3 \mathrm{~h}$ with labelled thymidine, beginning $15-21 \mathrm{~h}$ after antibody injection to ensure that any cycle of DNA synthesis in progress at the time of injection would have ended prior to labelling of the cells. Autoradiography would, therefore, reveal thymidine uptake only in cells able to initiate DNA synthesis following antibody injection.

To test the involvement of c-ras proteins in transformation, antibody was injected into NIH 3 T3 cells transformed by several oncogenes. An attempt was made to inject all transformed cells within a circular area marked on a coverslip; fluorescent antibodies that could recognize the injected immunoglobulin within the cells were used at the end of each experiment to determine which cells had been successfully injected ${ }^{16}$. Fluorescence staining also ensured that the injected antibody remained within the cell for the duration of the experiment. The proportion of injected cells able to incorporate thymidine was determined by comparing the results of fluorescent staining with those of autoradiography; this number was divided by the proportion of uninjected cells in S-phase on the same coverslip to give values for labelling efficiency ${ }^{16}$. The latter values indicate the percentage of injected cells which incorporated thymidine compared with the number expected to have been labelled if no injection had occurred. In all cells injected with control antibody 238 the labelling efficiency was between 85 and $115 \%$, with average values near $100 \%$; this was the case with each cell line tested here (data not shown) as well as with numerous cell lines tested in other studies ${ }^{14,16}$. A labelling efficiency close to $100 \%$ indicates that injected and uninjected cells enter S-phase with equal efficiency after injection of control antibody.

NIH 3 T3 cells were transformed with membrane-associated, receptor-like proteins $\left(s r c, f m s\right.$ and $\left.f e^{2,17-20}\right)$ by transfection of cloned viral DNA. Approximately $12-15 \mathrm{~h}$ after microinjection of antibody 259, a distinct morphological reversion from the transformed phenotype was observed in cells that had been transformed by each of the three viral oncogenes. Transformed 
cells that had a rounded or spindle-shaped morphology with a refractile appearance reverted to the flattened shape of untransformed NIH 3T3 cells. Figure 1 shows such reversion after injection into $s r c$-transformed cells. Morphological reversion continued until 30-50 h after injection (at which time injected antibody had disappeared from the cells); then the cells became morphologically transformed once again (data not shown $)^{13}$. In addition to its morphological effects, antibody 259 decreased dramatically the thymidine incorporation of transformed cells labelled during a 3-h pulse between 15 and $24 \mathrm{~h}$ after antibody injection. In Fig. $2 a-d$ the decrease in thymidine incorporation following injection of antibody into fms- and fes-transformed cells is clearly visible. Several different clones transformed by each oncogene were analysed. In each of the three transformants labelling efficiencies varied from 10 to $30 \%$ (Table $1 a$ ). For comparison, ras-transformed NIH 3T3 cells and untransformed NIH 3T3 cells had labelling efficiencies of $10-15 \%$ (Table 1). It is unknown whether the small difference in labelling efficiency between NIH 3T3 cells transformed by ras and those transformed by other oncogenes is significant.

Next, we analysed two representatives of the cytoplasmic class of retroviral oncogenes (mos and $r a f^{2,21-23}$ ). NIH 3T3 clones transformed by mos (from G. F. Vande Woude, R. B. Arlinghaus and R. H. Bassin) and cells infected with raf-containing murine sarcoma virus 3611 (aided by two separate helper viruses; prepared by U. R. Rapp) were injected with antibody as before. In no instance of repeated analysis was there any evidence that anti-ras antibody 259 altered the transformed morphology of these cells (data not shown). In addition, labelling efficiencies of mos- and raf-transformed cells were between 90 and $96 \%$ (Table $1 a$ ); this indicates that proliferation was inhibited little, if at all, by injected antibody, as shown in Fig. $2 g, h$, where a direct comparison can be made with cells transformed by other oncogenes. The average labelling efficiency obtained with control antibody 238 was consistently within a few per cent of $100 \%$ (data not shown ${ }^{14,16}$ ). It is unknown how these oncogenes overcome the normal requirement for c-ras in cellular proliferation but it is clear that both representatives of this oncogene class are able to do so. The group of oncogenes that we have shown to depend on c-ras proteins during transformation is similar, but not identical, to those reported to be suppressed following fusion to flat revertants of viral ras-transformed cells ${ }^{24}$. Once more is understood about the molecular basis of the morphological reversion, we may find that the differences between the two systems are important.

In addition to retroviruses, several DNA viruses are able to transform cells. The transforming genes of these viruses are not closely related to the sequences of cellular genes or retroviral oncogenes but they may function similarly. These viruses commonly possess multiple transforming genes ${ }^{1}$. Transformation by these viruses displays differences in dependence on c-ras, just as observed with retroviral oncogenes. NIH $3 \mathrm{~T} 3$ cells transformed by one such virus, bovine papillomavirus (BPV; from D. R. Low $y^{25}$ ), were tested as described above, together with W138 and BALB 3T3 cells transformed by simian virus 40 (SV40). Antibody 259 clearly induced morphological reversion in BPV-transformed NIH 3 T3 cells (Fig. $2 e, f$ ) and reduced thymidine incorporation. While the antibody clearly inhibited entry into S-phase in cells transformed by BPV, the labelling efficiencies were normally between 26 and $45 \%$ (Table $1 b$ ). It is unknown whether the difference in labelling efficiencies between cells transformed by this virus and those transformed by the membrane-associated oncogenes is significant. In cells transformed by SV40, on the other hand, the anti-ras antibody inhibited proliferation little if at all. While both cell types tested are efficiently inhibited by the antibody prior to transformation $^{16}$, labelling efficiencies after SV40 transformation were 86 and $93 \%$, similar to those observed with the mos and raf oncogenes. It may not be possible at present to make a thorough comparison between the oncogenes of DNA viruses and the
Table 1 Labelling efficiencies of NIH 3T3 cells transformed by various oncogenes

\begin{tabular}{|c|c|c|c|c|}
\hline Oncogene & Cell line & \multicolumn{2}{|c|}{$\begin{array}{l}\text { Labelling efficiency } \\
\text { Average } \\
( \pm \text { s.e.m.) }\end{array}$} & \multirow[t]{2}{*}{ Source } \\
\hline$a$ & & & & \\
\hline \multirow[t]{2}{*}{ fes } & NIH 3T3-fes* & $10(2.3)$ & 9 & C. J. Sherr ${ }^{19}$ \\
\hline & NIH 3T3-fes & $30(3.9)$ & 10 & R. H. Bassin \\
\hline \multirow[t]{2}{*}{ fms } & NIH 3T3-fms* & $17(3.0)$ & 5 & C. J. Sherr ${ }^{18}$ \\
\hline & NIH 3T3-fms & $21(4.9)$ & 7 & R. H. Bassin \\
\hline \multirow[t]{3}{*}{ mos } & MSV-124 & $90(10.0)$ & 5 & R. B. Arlinghaus \\
\hline & pHT1v-mos & $96(2.4)$ & 11 & D. G. Blair \\
\hline & NIH 3T3-mos & $93(2.5)$ & 7 & R. H. Bassin \\
\hline \multirow[t]{2}{*}{ raf } & $\begin{array}{l}\text { NIHF4-3611- } \\
\text { LeuK }\end{array}$ & $93(4.0)$ & 10 & U. R. Rapp \\
\hline & NIHF4-3611-4070 & $91(2.3)$ & 6 & U. R. Rapp \\
\hline \multirow[t]{3}{*}{ ras } & HA- $8-21$ & $10(1.8)$ & 4 & D. R. Lowy \\
\hline & HA- 8 & $12(8.0)$ & 2 & D. R. Lowy \\
\hline & RS-485 & $13(1.5)$ & 5 & E. H. Chang \\
\hline \multirow[t]{2}{*}{$s r c$} & NIH 3T3-src* & $27(4.1)$ & 3 & Ref. 29 \\
\hline & NIH 3T3-src & $23(3.0)$ & 11 & R. H. Bassin \\
\hline \multicolumn{5}{|l|}{$b$} \\
\hline \multirow[t]{2}{*}{ SV40 } & SVT2 + & $93(5.7)$ & 5 & ATCC \\
\hline & VA-13‡ & $86(3.3)$ & 8 & ATCC \\
\hline \multirow[t]{2}{*}{ BPV } & S-2 & $27(7.7)$ & 4 & D. R. Lowy \\
\hline & ID-14 & $26(3.0)$ & 4 & D. R. Lowy \\
\hline \multicolumn{2}{|c|}{ NIH 3T3 } & $10(1.3)$ & 7 & E. P. Reddy \\
\hline \multicolumn{2}{|c|}{ Swiss NIH $3 \mathrm{~T} 3$} & $15(3.0)$ & 2 & ATCC \\
\hline \multicolumn{2}{|c|}{ NIH $3 \mathrm{~T} 3$} & $14(1.3)$ & 7 & R. H. Bassin \\
\hline
\end{tabular}

Antibody 259 was microinjected into the cytoplasm of the cell types listed. Each cell type was derived from a cell clone. A 3-h pulse of ${ }^{3} \mathrm{H}$-thymidine between 18 and $24 \mathrm{~h}$ after injection was followed by fixation in methanol and staining with fluorescent antibody to identify injected cells ${ }^{16}$. The cell lines listed above were also injected with non-neutralizing antibody 238 . For antibody 238 injections, average labelling efficiencies were in the range 95-105\% (see text). NIH 3T3 cells transformed with the sis oncogen ${ }^{20}$ showed a labelling efficiency of $17 \pm 2 \%$. In transfected cells not characterized previously, a cloned cell population was analysed by Southern blotting to ensure that the viral oncogene had become incorporated into cellular DNA. Growth in soft agar and morphological examination verified that the transfected cells displayed the phenotypic characteristics of transformed cells. Labelling efficiencies were obtained by first determining the percentage of injected cells which had incorporated thymidine, then dividing this percentage by the percentage of uninjected cells on the same plate which were labelled.

* These cells were transformed by transfection ${ }^{29}$ of the viral oncogene described in the reference cited. Clones of transformed NIH 3T3 cells obtained in soft agar were tested by Southern analysis to ensure that the transfected oncogene had been incorporated into the cellular genome. At least three separate cell clones were analysed for each oncogene.

$\dagger$ Number of determinations, each of which averaged between 150 and 200 injected cells.

$¥$ These lines, obtained from the American Type Culture Collection, are SV40-transformed WI38 (VA-13) or BALB 3T3 (SVT2) cells. Both of these cell lines have labelling efficiencies close to $10 \%$ prior to transformation (ref. 16 and our unpublished data).

retroviral oncogenes tested here ${ }^{1}$, but these data indicate some similarities in their action.

Any conclusion drawn from the present study depends on the specificity of the cellular proteins neutralized by antibody 259 . As described above, this antibody neutralizes ras protein within the injected NIH $3 \mathrm{~T} 3 \mathrm{cell}^{13}$. However, it is possible that another cellular protein is also neutralized by the antibody. To ascertain that it is in fact c-ras proteins which are neutralized and responsible for the results described, we tested numerous tumour cell lines. In these tumour lines the phenotype of antibody inhibition strongly correlates with the presence of a mutant ras oncogene ${ }^{16}$. Furthermore, deletion mutants of the ras gene which are biologi- 
cally active but which do not bind antibody 259 have been prepared recently; cells transformed by such mutants were not altered morphologically, nor did they show greatly inhibited thymidine incorporation, after injection of antibody $259^{26}$.

It is assumed that while viral oncogenes function without normal control, their mechanism of action is similar to that of related cellular genes. Here we have presented evidence to support this idea in the case of growth factor receptor-like molecules and related oncogenes. It is therefore possible that these data might aid in understanding the way in which cellular genes interact in the control of normal proliferation. Our results indicate that some receptor-like oncogenes depend on ras proteins while some cytoplasmic oncogenes do not. There are, of course, numerous oncogenes which we have not yet tested which might behave differently from those described here. With this limitation in mind and on the basis of our present data, we propose that an important class of proliferative signals are received at the cell surface by receptor molecules such as growth factor receptors, and the c-ras proteins are essential in the transfer of these signals to cytoplasmic effectors having serine kinase activity; the effectors then modify target molecules which are directly involved in initiating a proliferative cycle. Accordingly, if the cytoplasmic effector were mutated such that it functioned without activation, proliferation would continue independently of c-ras proteins. Receptor molecules, on the other hand, would always require c-ras to stimulate proliferation.

While our data are consistent with the above scheme, they do not exclude many other possibilities involving multiple metabolic pathways and more complex interactions. For example, we have not reported results with nuclear oncogenes owing to their difficulty in transforming NIH $3 \mathrm{~T} 3$ cells. The proposed scheme is primarily attractive because of its similarity to the carefully studied mechanism of signal transduction involving cyclic AMP. While it is unlikely that cyclic AMP itself regulates proliferation ${ }^{27}$, G-regulatory proteins with enzymatic similarities to c-ras proteins are involved. These regulatory proteins control signal transduction from cell-surface receptors to cytoplasmic serine kinase effector molecules by regulating adenyl cyclase activity $^{28}$.

While the present study has examined only one aspect of what is likely to be a highly complex system for regulating proliferation, it does provide a means of functionally comparing separate viral oncogenes. Injection of antibody has been used in other studies to characterize the types of molecules responsible for tumour cell proliferation. Like NIH 3T3 cells transformed by mos or raf genes, many tumour cells show no inhibition of proliferation when injected with anti-ras antibody. In this way their proliferation is distinct from that of the normal cell types studied, each of which was efficiently inhibited by the injected antibody ${ }^{16}$.

This study relied on cell lines and plasmids prepared and characterized by several workers. In addition to those listed above, we thank H. Temin, G. Thornton, T. Papas, S. Goff and O. Witte for supplying materials. We also thank $\mathrm{T}$. Curran and H.-F. Kung for critical review of the manuscript and J. Hansen for technical assistance.

Received 30 October 1985; accepted 12 February 1986.

1. Bishop, J. M. Cell 42, 23-38 (1985)

2. Bishop, J. M. \& Varmus, H. E. in RNA Tumor Viruses: Molecular Biology of Tumor Viruses 2nd end (eds Weiss, R., Teich, M., Varmus, H. \& Coffin, J.) 999-1108 (Cold Spring Harbor Laboratory, New York, 1984).

3. Doolittle, F. R. et al. Science 221, 275-277 (1983)

4. Downward, J. et al. Nature 307, 521-527 (1984)

5. Waterfield, M. D. et al. Nature 304, 35-39 (1983)

6. Sherr, C. J. et al. Cell 41, 665-676 (1985).

7. Ellis, R. W. et al. Nature 292, 506-511 (1981).

8. Sweet, R. W. et al. Nature 311, 273-275 (1984)

9. McGrath, J. P. Capon, D. J., Goeddel, D. V. \& Levinson, A. D. Nature 310, 644-649 (1984).

10. Kloetzer, W. S., Maxwell, S. A. \& Arlinghaus, R. B. Virology 138, 143-155 (1984).

11. Moelling, K., Heimann, B., Beimling, P., Rapp, U. R. \& Sander, T. Nature 312, 558-561 (1984)

12. Papkoff, J., Nigg, E. A. \& Hunter, T. Cell 33, 161-172 (1983).
13. Kung, H.-F., Smith, M. R., Bekesi, E., Manne, V. \& Stacey, D. W. Expl Cell Res. 162, 363-371 (1986).

14. Mulcahy, L. S., Smith, M. R. \& Stacey, D. W. Nature 313, 241-243 (1985)

15. Furth, M. E., Davis, L. J., Fleurdelys, B. \& Scoinick, E. M. J. Virol. 43, 294-304 (1982).

16. Stacey, D. W., DeGudicibus, S. J. \& Smith, M. R. (in preparation).

17. Brugge, J. S. \& Erikson, R. L. Nature 269, 346-348 (1977).

18. Fedele, L. A., Even, J., Garon, C. F., Donner, L. \& Sherr, C. J. Proc. natn. Acad. Sci. U.S.A. 78, 4036-4040 (1981)

19. Donner, L., Fedele, L. A., Garon, C. F., Anderson, S. J. \& Sherr, C. J. J. Virol. 41, 489-500 (1982)

20. Robbins, K. C., Devare, S. G., Reddy, E. P. \& Aaronson, S. A. Science 218, 1131-1133 (1982)

21. Blair, D. G., McClements, W. L., Oskarsson, M. K., Fischinger, P. J. \& Vande Woude, G. F. Proc. natn. Acad. Sci. U.S.A. 77, 3504-3508 (1980).

22. Rapp, U. R. \& Todaro, G. J. Proc. natn. Acad. Sci. U.S.A. 77, 624-628 (1980).

23. Horn, J. R., Wood, T. G., Murphy, E. C., Blair, D. G. \& Arlinghaus, R. B. Cell 25, 37-46 (1981).

24. Noda, M., Selinger, Z., Scolnick, E. M. \& Bassin, R. H. Proc. natn. Acad. Sci. U.S.A. 80, 5602-5606 (1983).

25. Schiller, J. T., Vass, W. C. \& Lowy, D. R. Proc. natn, Acad. Sci. U.S.A. 81, 7880-7884 (1984)

26. Papageorge, A. G. et al. Molec, cell. Biol. (in the press).

27. Beckner, S. K., Hattori, S. \& Shih, T Y. Nature 317, 71-72 (1985).

28. Gilman, A. Cell 36, 577-579 (1984).

29. Wigler, M. et al Proc natn Acad. Sci. U.S.A. 76, 1373-1376 (1979)

\section{Viral particles induce Ia antigen expression on astrocytes}

\section{P. T. Massa, R. Dörries \& V. ter Meulen}

Institute of Virology and Immunobiology, University of Würzburg, Versbacherstrasse 7, D-8700 Würzburg, FRG

Recent studies have shown that $\gamma$-interferon (IFN- $\gamma$ ) induces the expression of Ia antigen on astrocytes ${ }^{1,2}$. This observation is of immunological significance because such activated astrocytes can act as antigen-presenting cells, as demonstrated with myelin basic protein for antigen-specific encephalitogenic $T$-cell lines ${ }^{3}$. However, the lack of lymphatic drainage in brain and the presence of the so-called blood-brain barrier restricting traffic of cells and macromolecules suggests that IFN- $\boldsymbol{y}$ may not be readily available, at least during the initial phases of viral infections. The question therefore arises as to whether astrocytes can be induced to express Ia antigens by other signals directly related to viral infection and possibly independent of IFN- $\gamma$. In the present report we demonstrate that a neurotropic murine hepatitis virus induces expression of Ia antigen on astrocytes in tissue culture without infection, rendering these brain cells competent to participate directly in the immune response to a viral infection.

The murine coronaviruses are a group of agents causing acute, subacute or chronic infections in mice or rats accompanied by different disease processes ${ }^{4}$. The JHM strain of this group is neurotropic and has been shown to induce acute or subacute encephalomyelitides which depend on virus as well as host factors ${ }^{5}$. One important factor in the case of subacute encephalomyelitis in Lewis rats is the immune response, which is directed not only against the virus but also against brain tissue $^{6}$. As various types of central nervous system (CNS) disease are associated with this neurotropic murine coronavirus strain, we chose this virus to define its interaction with rat brain cells in culture with respect to the induction of Ia antigen on astrocytes.

As a baseline for our study, we analysed the response of Lewis primary glial cell cultures consisting of macrophages carrying Fc receptors ( $\mathrm{Fc}$ receptor ${ }^{+}$) and astrocytes expressing glial fibrillary acidic protein (GFAP ${ }^{+}$) (Fig. $2 a-c$ ) to recombinant rat IFN- $\gamma\left(10 \mathrm{U} \mathrm{ml}^{-1}\right.$; Fig. $\left.1 a\right)$. Recombinant rat IFN- $\gamma$ induced the expression of Ia on numerous cells in the primary cultures. Fluorescence-activated cell sorting showed that $3-10 \%$ of the cells were induced to express Ia compared with the control after $18 \mathrm{~h}$ treatment with $10 \mathrm{U} \mathrm{ml}^{-1}$ IFN- $\gamma$, reaching a maximum at $48 \mathrm{~h}$, when $20 \%$ of all cells were induced (Fig. $1 a$ ). By immunofluorescence microscopy, $\mathrm{Ia}^{+}$cells also became apparent after $18 \mathrm{~h}$ of treatment whereas control cultures showed no $\mathrm{Ia}^{+}$cells. Double immunofluorescence microscopy revealed that 